\title{
HURRICANE HAZARD ASSESSMENT: CONSIDERATIONS FOR SEA-LEVEL RISE AND CLIMATE CHANGE
}

\author{
Jennifer L. Irish ${ }^{1}$, Celso Ferreira ${ }^{2}$, Donald T. Resio ${ }^{3}$, \\ Francisco Olivera ${ }^{4}$, and Chih Hung $\mathrm{Hsu}^{4}$
}

\begin{abstract}
Assessment of hurricane flooding risk is an essential component for effective coastal planning and engineering design. Existing methods for evaluating extreme-value flood statistics traditionally assume that flood conditions are stationary, such that historical information represents future conditions. However, dynamic changes in the environment, specifically changing sea levels and potential changes in hurricane intensity and rate of occurrence, mean that future flooding risk will not be adequately represented by historical conditions alone. In this paper, an approach is proposed for incorporating future sea level and hurricane climate projections into extreme-value flood probabilities and risk assessment.
\end{abstract}

Keywords: Storm surge; extreme-value statistics; hurricanes, risk

\section{INTRODUCTION AND BACKGROUND}

Here, the influence of long-term climate change on hurricane flooding statistics is considered. The impact of long-term future climate change is difficult to quantify with a high degree of certainty. However, a growing body of literature supports a future global warming trend. The Intergovernmental Panel on Climate Change (IPCC 2007) reported sea-surface temperature (SST) rise projections of 1.1 ${ }^{\circ} \mathrm{C}$ to $6.4{ }^{\circ} \mathrm{C}$ over the next century. With potential global warming, the IPCC (2007) concluded that sealevel rise $(S L R)$ will most likely continue to accelerate, with $S L R$ projections for the next century being 0.18 to $0.60 \mathrm{~m}$; others reported $S L R$ projections of more than $1 \mathrm{~m}$ over the next century when major ice-sheet melting is considered (e.g., Overpeck et al. 2006; Pfeffer et al. 2008; Rahmstorf 2007).

Climatology analyses support the hypothesis that tropical cyclones will intensify with global warming (e.g., Elsner et al. 2008; Emanuel et al. 2008; Knutson and Tuleya 2008; Vecchi and Soden 2007; Webster et al. 2005). Knutson et al. (2010) summarized the results of these studies by concluding that tropical cyclone wind intensity is expected to increase by 2 to $11 \%$ by 2100 . While hurricanes are expected to intensify with global warming, recent studies concluded that the rate of occurrence of hurricanes might diminish with global warming. By review of a number of tropical cyclone frequency forecasting studies (e.g., Bengtsson et al. 2007; Gualdi et al. 2008; Oouchi et al. 2006; Zhao et al. 2009), Knutson et al. (2010) concluded that tropical cyclone frequency will either remain unchanged or decrease somewhat with future global warming, by 6 to $34 \%$ by 2100 .

In the following, we present a method for assessing future hurricane flooding and damage statistics, with sample results shown for the Houston-Galveston region along the United States Gulf of Mexico coastline.

\section{STUDY AREA}

The study area is the Houston-Galveston coastline along the northern United States Gulf of Mexico (Figure 1). This area is highly populated and supports an array of industries, including oil and gas and tourism. This region is also prone to hurricane activity, and much of the coastal area is low-lying, making the region susceptible to coastal flooding. Surge generation in this region is dominated by wind surge, due to the rapidly widening continental shelf offshore of the study area. Over the last half decade, this region has been impacted by surges generated by Hurricanes Katrina, Rita, and Ike. The most recent significant flooding event was Hurricane Ike, which made landfall as a Category 2 hurricane in September 2008. This storm devastated the coastal region, and was associated with surges in excess of $4 \mathrm{~m}$ along much of the study area.

\footnotetext{
${ }^{1}$ Civil and Environmental Engineering, Virginia Tech, 221D Patton Hall, Blacksburg, VA, 24061, USA

${ }^{2}$ Civil Engineering, George Mason University, 1300 Nguyen Engineering Building, Fairfax, VA, 22030, USA. Formerly with Civil Engineering, Texas A\&M University.

${ }^{3}$ Computing, Engineering, and Construction, University of North Florida, 1 UNF Drive, Jacksonville, FL, 32224, USA

${ }^{4}$ Civil Engineering, Texas A\&M University, 3136 TAMU, College Station, TX, 77843, USA
} 


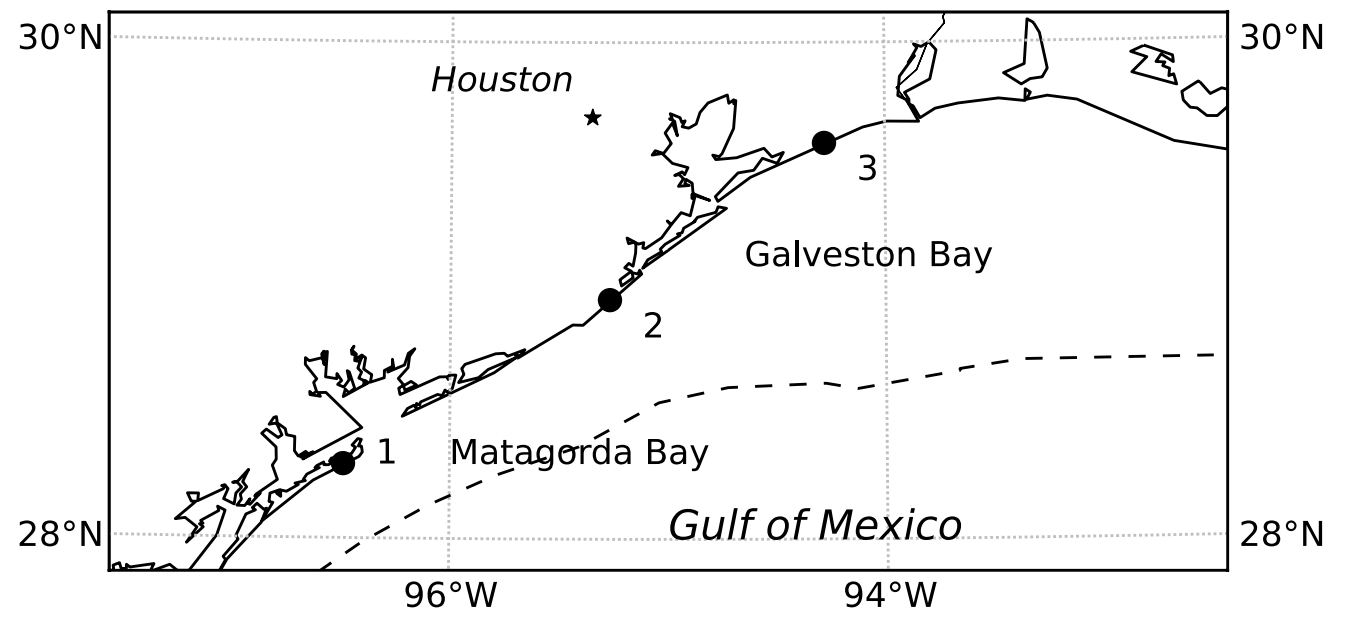

Figure 1. Location map, where the Houston-Galveston study area lies between locations 1 and 3. The shoreline is given by the solid line while the $30-\mathrm{m}$ depth contour is given by the dashed line.

\section{METHODS}

Future-Climate Surge Prediction with Surge Response Functions (SRF)

Peak hurricane flood elevation at some location $x, z_{\max }(x)$, is a function of hurricane meteorological conditions, future SST and mean sea level (MSL) conditions, and regional and local topographic conditions. Thus, flood elevation can be written as (Irish and Resio in press):

$$
z_{\max }(x, S S T)=\phi\left(x, p_{o}(S S T), R, v_{f}, \theta, x_{o}, M S L(S S T)\right)+\varepsilon_{z}
$$

where $\phi$ is a continuous flood response function, $x$ is location of interest, $x_{o}$ is landfall location, $R$ is hurricane radius, $\theta$ is hurricane track angle with respect to the shoreline, $v_{f}$ is hurricane forward speed near landfall, and $\varepsilon_{z}$ is epistemic uncertainty in the flood response (Resio et al. 2009; Resio et al. in press). Here, analysis is limited to open-coast water levels; thus we will assume that the total flood elevation in the future may be represented by the product of the storm surge $\left(\zeta_{\max }\right)$ and change in $M S L$ $(\triangle M S L)$, such that $\phi=\zeta_{\max }+\Delta M S L$. We will further assume that the effects of track angle and forward speed on surge generation are small, with respect to other factors. For this case, $\zeta_{\max }$ may be estimated from the dimensionless, algebraic surge response functions of Song et al. (in press):

$$
\begin{gathered}
\zeta^{\prime}=\frac{\gamma \zeta_{\max }}{\left(p_{\text {far }}-p_{o}\right)}+m\left(x, x^{\prime}\right)\left(\frac{p_{\text {far }}-p_{o}}{p_{\text {far }}-p_{o-\min }}\right)^{\alpha\left(x, x^{\prime}\right)}\left(\frac{R / L\left(x_{o}\right)}{[R / L]_{r e f}}\right)^{\alpha\left(x, x^{\prime}\right)} \\
x^{\prime}=\frac{\left(x-x_{o}\right)}{R}-\lambda\left(x_{o}\right)+c H\left(\frac{\left(x-x_{o}\right)}{R}-\lambda\left(x_{o}\right)-1\right) H\left(\frac{L\left(x_{o}\right)}{L_{r e f}}-1\right)\left(\frac{R}{L\left(x_{o}\right)}\right)-F\left(1-\frac{R}{R_{\text {thres }}}\right)
\end{gathered}
$$

where $p_{\text {far }}$ is far-field barometric pressure, $L$ is cross-shore distance from the shoreline to the $30-\mathrm{m}$ depth contour, $H$ is the Heaviside step function, $F$ is a kernel function, and the remaining parameters are location-specific constants. See Song et al. (in press) and Irish et al. (2009) for full details on SRF development. The above model may be used to specify continuous probability density functions on flood elevation for extreme-value analysis using a joint-probability approach (Resio et al. 2009). For the case of a changing future climate, Irish and Resio (in press) proposed:

$$
f\left(S S T, p_{o}, R, x_{o}\right)=\Lambda_{S S T} \Lambda_{p_{o}} \Lambda_{R} \Lambda_{x_{o}}
$$

where the $\Lambda$ functions are the joint probabilities. Here, we will assume that (1) $\Lambda_{R}$ is normally distributed with a dependence on $p_{o}$; (2) $\Lambda_{\mathrm{xo}}$ equals the storm rate of occurrence, uniformly distributed 
along the coast; (3) $\Lambda_{\text {po }}$ follows a Gumbel distribution, where the fit coefficients $a_{o}$ and $a_{l}$ are allowed to slowly vary in time:

$$
\begin{aligned}
\Lambda_{p_{o}} & =f\left(p_{o} \mid x_{o}, \Delta S S T\right) \\
& =\frac{1}{a_{1}\left(x_{o}, \Delta S S T\right)} \exp \left[-\frac{\Delta p-a_{o}\left(x_{o}, \Delta S S T\right)}{a_{1}\left(x_{o}, \Delta S S T\right)}\right] \exp \left\{-\exp \left[-\frac{\Delta p-a_{o}\left(x_{o}, \Delta S S T\right)}{a_{1}\left(x_{o}, \Delta S S T\right)}\right]\right\}
\end{aligned}
$$

where $\Delta p=p_{\text {far }}-p_{o}$ and $\Delta S S T$ is $S S T$ change; and (4) $\Lambda_{\mathrm{SST}}$ is uniformly distributed across all sensitivities for a given future climate storyline, where $S S T$ values slowly vary in time. Finally, the MSL is assumed to correlate directly with SST. See Irish and Resio (in press) and Resio et al. (2009) for full details on the joint probability method with optimal sampling using SRFs.

The impact of SST rise on MSL and hurricane central pressure are assessed, while future changes in hurricane intensity are not considered. We considered the IPCC (2007) A1B storyline, which assumes a future balanced allocation of energy sources with moderated future carbon emissions. The climate model MAGICC/SCENGEN (Wigley 2004; personal communications Joel Smith of Stratus Consulting) was used to develop estimates of future $S S T$ rise and eustatic SLR for two time periods, the 2040s and 2080s (Table 1), while current-day results are assumed to represent the 2000s. The following simplified relationship was employed to estimate hurricane central pressure decrease with SST rise (Knutson and Tuleya 2008):

$$
p_{o-\Delta S S T}=p_{o-2000 s}-0.08 \Delta S S T\left(p_{\text {far }}-p_{o-2000 s}\right)
$$

\begin{tabular}{|c|c|c|}
\hline & SST rise $\left({ }^{\circ} \mathrm{C}\right)$ & $\operatorname{SLR}(\mathrm{m})$ \\
\hline 2040s, low estimate & 0.58 & 0.11 \\
\hline 2040s, high estimate & 1.80 & 0.22 \\
\hline 2080s, low estimate & 1.28 & 0.25 \\
\hline 2080s, high estimate & 3.80 & 0.51 \\
\hline
\end{tabular}

where $p_{o-\Delta S T}$ is the adjusted central pressure corresponding to $\Delta S S T$, and $p_{o-2000 s}$ is the current day $p_{o}$.

\section{Damage Estimation}

Potential economic damages were assessed from within a geographic information system, following the methods presented in Frey et al. (2010). Several simplifying assumptions were employed:

1. Economic damages were based on available relationships between flood depth and damage within the Federal Emergency Management Agency's (FEMA) HAZUS database (FEMA 2009).

2. Damage to residential, commercial, industrial, public, and agricultural structures were based on information contained in the HAZUS General Building Stock Database (FEMA 2009).

3. Inundated area was determined by intersecting the predicted surge with U.S. Geological Survey 10-m digital elevation model.

4. To simplify the analysis, damage calculation was limited to the open coastal zone extending 1.6 $\mathrm{km}$ inland from the open coast, such that damages in more inland coastal regions along estuaries and bays were ignored.

The Houston-Galveston coastline was segmented into $10-\mathrm{km}$ segments, and then damages were tabulated by segment based on surge elevations above mean sea level of 1.5, 3.0, 4.6, 6.1, and 7.6 m. Statistical estimation of damages were made by evaluating damages associated with each surge probability. Estimated annual damages were computed by integrating the damage-frequency curve.

\section{RESULTS AND CONCLUSIONS}

Flood elevation versus return period estimates were developed for three open-coast locations in the Houston-Galveston area (see Figure 1; Song et al. in press); estimates were developed for the decades of the 2000s (current day), 2040s, and 2080s (Figure 2). In this area, flood elevations are estimated to increase by 10 to $14 \%$ by the 2040 s and by 21 to $30 \%$ by the $2080 \mathrm{~s}$. Most extreme flood elevations 
during all time periods are expected in the northeastern portion of the study area. Along the open coast estimated annual damages are estimated to increase by about $20 \%$ by the 2040 s and by about $40 \%$ by the 2080 s.
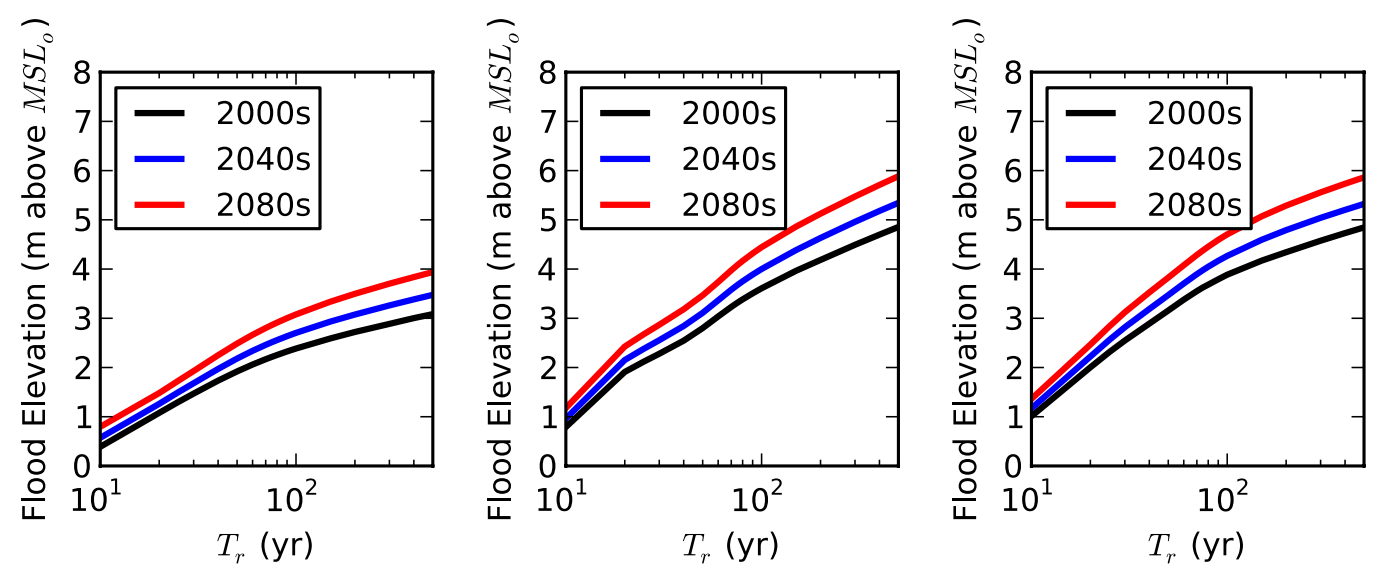

Figure 2. Estimated flood elevation versus return period for locations 1 (left) through 3 (right) for the A1B climate storyline for the following decades: 2000s (current day), 2040s, and 2080s. Flood elevation values are presented with respect to current day mean sea level $\left(M S L_{\circ}\right)$.

The results presented here are intended to be illustrative only. It is important to note that, based on historical trends, relative $S L R$ in the Houston-Galveston area is anticipated to exceed the eustatic rate. As such, the implications of $S L R$ on future flooding statistics will be more severe than what is indicated in this analysis. Furthermore, the estimated annual damages do not consider possible damages in highly populated inland areas, most notably the Houston metro area. Actual damages will depend on the distribution of construction, with respect to proximity to vulnerable areas and with respect to topographic elevation.

Nonetheless, these illustrative results demonstrate the importance of planning for future sea level and climate trends. Even when a moderated carbon emissions scenario is assumed, the potential for increased economic damages is dramatic. Whenever possible, it is recommended that adaptive management strategies be considered as a means to minimize under- or over-design as a result of uncertainty in mean climate trends (Irish and Resio in press). In closing, the methods presented here present a practical method for assessing future changes in the hurricane flood hazard.

\section{ACKNOWLEDGMENTS}

The authors wish to thank Dr. Thomas R. Knutson (Geophysical Fluid Dynamics Laboratory, National Oceanic and Atmospheric Administration) for helping us to interpret future climate trends and Mr. Joel Smith (Stratus Consulting) for providing MAGICC/SCENGEN simulation results. This research was supported by the Office of Science (BER) U.S. Department of Energy (Grant No. DEFG02-08ER64644), the National Sea Grant College Program of the U.S. Department of Commerce's National Oceanic and Atmospheric Administration (Grant No. NA10OAR4170099), and the South Atlantic Landscape Conservation Cooperative (Grant No. 24036078). The views expressed herein do not necessarily reflect the views of any of these organizations.

\section{REFERENCES}

Bengtsson, L., Hodges, K. I., Esch, M., Keenlyside, N., Kornblueh, L., Luo, J. J., and T. Yamagata. 2007. How may tropical cyclones change in a warmer climate?, Tellus Series a-Dynamic Meteorology and Oceanography, 59(4), 539-561.

Elsner, J. B., Kossin, J. P., and T. H. Jagger. 2008. The increasing intensity of the strongest tropical cyclones, Nature, 455(7209), 92-95.

Emanuel, K., Sundararajan, R., and J. Williams. 2008. Hurricanes and global warming - Results from downscaling IPCC AR4 simulations, Bulletin of the American Meteorological Society, 89(3), 347-367.

Federal Emergency Management Agency. 2009. HAZUS FEMA's Methodology for Estimating Potential Losses from Disasters, Federal Emergenyc Management Agency report. 
Frey, A. E., Olivera, F., Irish, J. L., Dunkin, L. M., Kaihatu, J. M., Ferreira, C. M., and B. L. Edge. 2010. Potential Impact of Climate Change on Hurricane Flooding Inundation, Population Affected and Property Damages in Corpus Christi, Journal of the American Water Resources Association, 46(5), 1049-1059.

Gualdi, S., Scoccimarro, E., and A. Navarra. 2008. Changes in Tropical Cyclone Activity due to Global Warming: Results from a High-Resolution Coupled General Circulation Model, Journal of Climate, 21(20), 5204-5228.

Intergovernmental Panel on Climate Change. 2007. Intergovernmental Panel on Climate Change Fourth Assessment Report Working Group 1 Report: The physical science basis, Intergovernmental Panel on Climate Change report.

Irish, J. L., and D. T. Resio. In press. A method for estimating future hurricane flood probabilities and associated uncertainty, Journal of Waterway Port Coastal and Ocean Engineering-ASCE, DOI: $10.1061 /(A S C E) W W .1943-5460.0000157$.

Irish, J. L., Resio, D. T., and M. A. Cialone. 2009. A surge response function approach to coastal hazard assessment. Part 2: Quantification of spatial attributes of response functions, Natural Hazards, 51(1), 183-205.

Knutson, T. R., McBride, J. L., Chan, J., Emanuel, K., Holland, G., Landsea, C., Held, I., Kossin, J. P., Srivastava, A. K., and M. Sugi. 2010. Tropical cyclones and climate change, Nature Geoscience, 3(3), 157-163.

Knutson, T. R., and R. E. Tuleya. 2008. Tropical cyclones and climate change: revisiting recent studies at GFDL, in Climate Extremes and Society, H. Dias and R. Murnane, eds., Columbia University Press, New York, 120-144.

Mousavi, M. E., Irish, J. L., Frey, A. E., Olivera, F., and B. L. Edge. 2011. Global warming and hurricanes: the potential impact of hurricane intensification and sea level rise on coastal flooding, Climatic Change, 104(3-4), 575-597.

Oouchi, K., Yoshimura, J., Yoshimura, H., Mizuta, R., Kusunoki, S., and A. Noda. 2006. Tropical cyclone climatology in a global-warming climate as simulated in a $20 \mathrm{~km}$-mesh global atmospheric model: Frequency and wind intensity analyses, Journal of the Meteorological Society of Japan, 84(2), 259-276.

Overpeck, J. T., Otto-Bliesner, B. L., Miller, G. H., Muhs, D. R., Alley, R. B., and J. T. Kiehl. 2006. Paleoclimatic evidence for future ice-sheet instability and rapid sea-level rise, Science, 311(5768), 1747-1750.

Pfeffer, W. T., Harper, J. T., and S. O'Neel. 2008. Kinematic constraints on glacier contributions to 21st-century sea-level rise, Science, 321(5894), 1340-1343.

Rahmstorf, S. 2007. A semi-empirical approach to projecting future sea-level rise, Science, 315(5810), 368-370.

Resio, D. T., Irish, J. L., and M. A. Cialone. 2009. A surge response function approach to coastal hazard assessment. Part 1: Basic concepts, Natural Hazards, 51(1), 163-182.

Resio, D. T., Irish, J. L., Westerink, J. J., and N. Powell. In press. The effect of uncertainty on estimates of hurricane surge hazards, Natural Hazards.

Song, Y. K., Irish, J. L., and I. E. Udoh. In press. Regional attributes of hurricane surge response functions for hazard assessment, Natural Hazards, DOI:10.1007/s11069-012-0309-z.

Vecchi, G. A., and B. J. Soden. 2007. Effect of remote sea surface temperature change on tropical cyclone potential intensity, Nature, 450(7172), 1066-1070.

Webster, P. J., Holland, G. J., Curry, J. A., and H. R. Chang. 2005. Changes in tropical cyclone number, duration, and intensity in a warming environment, Science, 309(5742), 1844-1846.

Wigley, T. M. L. 2008. Magicc/Scengen 5.3. User Manual (version 2). National Center for Atmospheric Research report.

Zhao, M., Held, I. M., Lin, S. J., and G. A. Vecchi. 2009. Simulations of Global Hurricane Climatology, Interannual Variability, and Response to Global Warming Using a 50-km Resolution GCM, Journal of Climate, 22(24), 6653-6678. 